\title{
Current issues with prediction rules for syncope
}

\author{
Steve W. Parry MBBS PhD
}

See related research article by Saccilotto and colleagues at www.cmaj.ca/lookup/doi/10.1503/cmaj.101326 and synopsis on page 1721 .

Competing interests: Steve Parry was involved as a contributor to the 2009 guidelines on the diagnosis and management of syncope issued by the European Society of Cardiology.

This article was solicited and has not been peer reviewed.

Correspondence to: Dr. Steve W. Parry, swparry@hotmail.com, steve.parry@ nuth.nhs.uk

CMAJ 2011. DOI:10.1503 /cmaj.111529

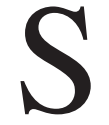
yncope (transient loss of consciousness with loss of postural tone, collapse and spontaneous recovery) is a serious public health issue, accounting for $1 \%-6 \%$ of visits to emergency departments ${ }^{1,2}$ and up to $6 \%$ of admissions to acute care hospitals. ${ }^{3}$ The frontline clinician assessing a person with syncope often faces a difficult choice: Can the patient be safely discharged, or should he or she be admitted for in-patient monitoring and investigation? Traditionally such choices have remained the province of clinical judgment, but in recent years, interest has grown in the development of prediction rules aimed at the efficient management and discharge planning for patients presenting to emergency departments with syncope. In a related research article, Saccilotto and colleagues bring some much needed objectivity to this issue through their systematic review and meta-analysis of one such prediction rule. ${ }^{4}$

Syncope prediction rules were developed to evaluate the likelihood of short-term serious outcomes or death using simple scoring systems that depend on electrocardiogram (ECG) findings, the presence of heart disease and other relevant variables. The rules currently available are difficult to evaluate, in part because different studies have placed different weights on the number and type of variables contributing to the scoring systems, and in part because application strategies and patient populations have varied widely. Meta-analyses and systematic reviews are of course powerful evaluation tools, but because of heterogeneity of study design and outcome assessment in syncope, authors need to justify completely their inclusions and exclusions; otherwise the effect of "comparing apples and oranges" becomes a powerful limiting factor.

To a large extent, Saccilotto and colleagues succeed in presenting a cogent view of the available literature, although the underrepresentation of older patients in the studies is of concern. This is not simply an academic exercise: although the lifetime prevalence of syncope has been estimated to be $42 \%$ of the general population, ${ }^{2}$ there is a threefold rise in incidence with advancing age, from an overall incidence of 6.2 per 1000 person-years to 18 per 1000 person-years among people 80 years and older. 5

Cardiac causes of syncope are disproportionately represented among patients over 60 . Observational data have shown that up to $30 \%$ of such individuals have an underlying cardiac arrhythmic or structural cause, compared with less than $5 \%$ of younger patients. ${ }^{2}$ Cardiac and other serious outcomes (adjusted for comorbidity) are also much more common among older patients with syncope (adjusted odds ratio 3.8, 95\% confidence interval $1.2-12$, for patients over 60 years compared with patients 18-39). ${ }^{6}$

This increased risk among older patients is particularly important given the main finding reported by Saccilotto and colleagues, ${ }^{4}$ namely that the San Francisco Syncope Rule (Box 1) is the most adequately validated across various populations, ${ }^{8}$ a finding echoed in a recent, similar meta-analysis.. As the authors point out, although the San Francisco Syncope Rule can aid decision-making at triage in emergency departments, it should be used only in tandem with a detailed clinical assessment, particularly in older individuals. Several studies have shown that this rule may miss arrhythmias and other serious outcomes in older patients. In a retrospective study involving 517 patients 65 years and older who presented to the emergency department with syncope, 23 of the 98 who experienced a serious outcome had a negative score with the rule; 17 of these 23 had arrhythmia despite having presented with normal ECG findings..$^{10} \mathrm{~A}$ prospective validation study of the San Francisco rule similarly showed that $26 \%$

All editorial matter in CMAJ represents the opinions of the authors and not necessarily those of the Canadian Medical Association. 
of patients who subsequently had a poor outcome were initially misclassified as being at low risk. ${ }^{11}$

Comparisons of outcomes using syncope prediction rules and careful clinical assessment sound a further note of caution. In two prospective studies, clinician judgment was found to perform as well as the San Francisco Syncope Rule $^{12,13}$ and the OESIL (Osservatorio Epidemiologico sulla Sincope nel Lazio) risk score ${ }^{13}$ in determining whether a patient would have an adverse outcome. Another study, however, showed that application of the San Francisco Syncope Rule would have increased the rate of hospital admission by $9 \%$ in a cohort of older patients with syncope compared with usual clinical care. ${ }^{14}$

So where does this leave busy clinicians trying to best serve their patients with syncope? Risk stratification tools, with guidance on determining need for hospital admission, associated length of stay and which tests to perform, are at best imperfect for the management of patients with syncope. Educated clinician judgment based on evidence-based guidelines (e.g., those published by the European Society for Cardiology, ${ }^{2}$ algorithms published by our group ${ }^{3}$ and guidelines from the United Kingdom's National Institute for Clinical Excellence ${ }^{15}$ ) seem to be the best strategy for management. Patients first need to be carefully assessed to see if their history suggests true syncope, as defined in the opening paragraph. A basic evaluation is then needed to find features of their history, examination results and ECG findings that are suggestive of cardiac versus noncardiac causes of the syncope. Further triage, referrals and investigation may be required from this initial review.

Syncope prediction rules can certainly aid this process, but they are not yet fit for use alone for

\section{Box 1: The San Francisco Syncope Rule ${ }^{7}$}

The San Francisco Syncope Rule is a simple rule for evaluating the risk of a serious short-term (within 30 days) outcome in a patient who presents to the emergency department with syncope. The mnemonic for features of the rule is CHESS:

- C - History of congestive heart failure

- $\mathrm{H}$ - Hematocrit < $30 \%$

- E-Abnormal findings on ECG or cardiac monitoring (new changes or nonsinus rhythm)

- $\mathrm{S}$-Shortness of breath

- $\mathrm{S}$-Systolic blood pressure $<90 \mathrm{~mm} \mathrm{Hg}$ at triage

The presence of any of the above risk factors mandates hospital admission and further monitoring and investigation.

Note: $E C G$ = electrocardiogram. risk stratification in any population, particularly older patients, in whom cardiac syncope (with its associated excess morbidity and mortality) is more likely.

Much of the evidence presented by Saccilotto and colleagues is difficult to assess because of the heterogeneity of study design and the use of short-term mortality and serious outcomes (e.g., myocardial infarction and stroke) as proxies for the sensitivity and specificity of the prediction rules being evaluated. The risk of subsequent syncopal events, the potential for injury, the need for immediate treatment in hospital (e.g., thrombolysis for pulmonary embolism, and implantable cardiac defibrillators) as well as what happens to patients following discharge are ignored by prediction rules. Arguably these issues are also important in terms of patient management.

\section{References}

1. Day SC, Cook EF, Funkenstein $\mathrm{H}$, et al. Evaluation and outcome of emergency room patients with transient loss of consciousness. Am J Med 1982;73:15-23.

2. Task Force for the Diagnosis and Management of Syncope of the European Society of Cardiology (ESC). Guidelines for the diagnosis and management of syncope (version 2009). Eur Heart J 2009;30:2631-71.

3. Parry SW, Frearson R, Steen N, et al. Evidence-based algorithms and the management of falls and syncope in the acute medical setting. Clin Med 2008;8:157-62.

4. Saccilotto RT, Nickel CH, Bucher HC, et al. San Francisco Syncope Rule to predict short-term serious outcomes: a systematic review. CMAJ 2011;183:E1116-26.

5. Soteriades ES, Evans JC, Larson MG, et al. Incidence and prognosis of syncope. N Engl J Med 2002;347:878-85

6. Sun BC, Hoffman JR, Mangione CM, et al. Older age predicts short-term, serious events after syncope. J Am Geriatr Soc 2007; 55:907-12.

7. Quinn JV, Stiell IG, McDermott DA, et al. Derivation of the San Francisco Syncope Rule to predict patients with short-term serious outcomes. Ann Emerg Med 2004;43:224-32.

8. Quinn J, McDermott D, Stiell I, et al. Prospective validation of the San Francisco Syncope Rule to predict patients with serious outcomes. Ann Emerg Med 2006;47:448-54.

9. Serrano LA, Hess EP, Bellolio MF, et al. Accuracy and quality of clinical decision rules for syncope in the emergency department: a systematic review and meta-analysis. Ann Emerg Med 2010;56:362-73.e1.

10. Schladenhaufen R, Feilinger S, Pollack M, et al. Application of San Francisco Syncope Rule in elderly ED patients. Am J Emerg Med 2008;26:773-8.

11. Birnbaum A, Esses D, Bijur P, et al. Failure to validate the San Francisco Syncope Rule in an independent emergency department population. Ann Emerg Med 2008;52:151-9.

12. Quinn JV, Stiell IG, McDermott DA, et al. The San Francisco Syncope Rule vs physician judgment and decision making. Am J Emerg Med 2005;23:782-6.

13. Dipaola F, Costantino G, Perego F, et al.; STePS Investigators. San Francisco Syncope Rule, Osservatorio Epidemiologico sulla Sincope nel Lazio risk score, and clinical judgment in the assessment of short-term outcome of syncope. Am J Emerg Med 2010;28:432-9.

14. Cosgriff TM, Kelly AM, Kerr D. External validation of the San Francisco Syncope Rule in the Australian context. CJEM 2007; 9:157-61.

15. National Institute of Clinical Excellence. Transient loss of consciousness (TLOC) management in adults. NICE guideline. London (UK): The Institute; 2010.

Affiliations: Steve Parry is with the Institute for Ageing and Health, Newcastle University, and the Falls and Syncope Service, Royal Victoria Infirmary, Newcastle, UK. 